Research Article

\title{
A Study of Acute Kidney Injury among the Patients with Snakebite in a Tertiary Care Hospital
}

\author{
Abhishek KB', Kadubandi Sunil Kumar ${ }^{2}$, Ramesh B ${ }^{3}$ \\ ${ }^{1}$ Assistant Professor, Department of Emergency Medicine, Chamarajangara Institute of Medical Sciences, Chamarajanagara, \\ Karnataka, India. \\ ${ }^{2}$ Civil Assistant Surgeon Specialist, MBBS, MD (Internal Medicine), CHC, Seethampeta, Andhra Pradesh, India. \\ ${ }^{3}$ Professor and Head, Dept. of General Medicine, Chamarajangara Institute of Medical Sciences, Chamarajanagara, Karnataka, \\ India. \\ DOI: https://doi.org/10.24321/2349.7181.202117
}

I $\mathbf{N}$ F $\mathbf{O}$

\section{Corresponding Author:}

Kadubandi Sunil Kumar, MD (Internal Medicine), $\mathrm{CHC}$, Seethampeta, Andhra Pradesh, India.

E-mail Id:

sunilkumar22@gmail.com

Orcid Id:

https://orcid.org/0000-0002-4064-0139

How to cite this article:

Abhishek KB, Kumar KS, Ramesh B. A Study of Acute Kidney Injury among the Patients with Snakebite in a Tertiary Care Hospital. J Adv Res Med. 2021;8(4):12-16.

Date of Submission: 2021-12-15

Date of Acceptance: 2022-01-12

\section{$\begin{array}{llllllll}\mathbf{A} & \mathbf{B} & \mathbf{S} & \mathbf{T} & \mathbf{R} & \mathbf{A} & \mathbf{C} & \mathbf{T}\end{array}$}

Background: The clinical presentation of a snakebite victim varies with the age and size of the patient, the species of snake, the number and location of the bites, the quantity and toxicity of the venom. The exact pathogenesis of Acute kidney injury (AKI) following snakebite is not well established, due to the lack of a reproducible animal model. The factors that may contribute are: direct cytotoxicity, bleeding, hypotension, circulatory collapse, intravascular hemolysis, disseminated intravascular coagulation and microangiopathic hemolytic anemia (MAHA).

Objective: To analyze various factors, influencing the outcome in patients of snakebite with acute kidney injury.

Materials and Method: The present prospective study was conducted in the Department of Emergency Medicine at M S Rammaih Medical College Bengaluru from August 2017 to September 2018. A total of 100 study subjects who met the inclusion criteria (patients with history of snakebite presenting with acute kidney injury) were included in the study. Patients underwent physical examination daily. Pulse rate, blood pressure, urine output, respiratory rate and features of envenomation were monitored daily. Blood specimen was taken every day till discharge or death to measure sodium, potassium, urea, creatinine, bleeding time, clotting time, platelets and for patients undergoing dialysis, pre-dialysis and post-dialysis urea and creatinine was measured for each cycle.

Results: Age, Gender, and Presence of Cellulitis does not influence the mortality in patients with Acute Kidney Injury. Early therapy with Anti-snake venom was associated with better outcome in terms of mortality. Early institution of dialysis had definite favourable outcome in Acute Kidney Injury. All patients with Acute Kidney Injury showed autopsy findings of renal involvement. Conclusion: In the present study, viper bite accounted for definite acute kidney injury. Major risk factors linked with adverse outcome in snakebite with Acute Kidney Injury were hypotension, bleeding manifestations and delayed specific therapy with anti-snake venom.

Keywords: Snakebite, Anti-Snake Venom, Renal Failure, Nephrotoxic

Journal of Advanced Research in Medicine (P-ISSN: 2394-7047 \& E-ISSN: 2349-7181) 


\section{Introduction}

Snakes are fascinating part of nature. Their colour, movement, and secret habits make them more mysterious. India is home to some of the most poisonous snakes in the world, most of which are found in rural areas. ${ }^{1}$ Snakebite poisoning is a preventable health hazard in tropics. It accounts for 100-150 deaths per day in India and the annual deaths per year is around $30,000 .{ }^{1}$ Snakebites cause substantial mortality and morbidity in India. A large proportion of snakebites occur when people are working barefoot in the fields, or while walking at night or early morning through fields or along roads. ${ }^{2}$

Our venomous species belong to two major families: Elapidae, Viperidae. We observe acute kidney injury (AKI) in majority of the cases. However, the gravity, spectrum, and the outcome of renal failure varies.

The exact pathogenesis of AKI following snakebite in not well established, due to the lack of a reproducible animal model. The factors that may contribute to AKI are: direct cytotoxicity, bleeding, hypotension, circulatory collapse, intravascular hemolysis, disseminated intravascular coagulation and microangiopathic hemolytic anemia (MAHA). ${ }^{3}$

Experimental studies with I 125-labeled E. carinatus venom ${ }^{4}$ and the demonstration of venom antigen in human victims of snakebite using Enzyme Linked Immuno Sorbent Assay technique have shown that the venom is excreted in the urine, without necessarily causing any damage to the kidney. Urinary beta- $\mathrm{N}$ acetylglucosaminidase showed considerable change in patients bitten by Russell's viper, without DIC, indicating a direct toxic effect of venom on the kidney. ${ }^{5}$

In a study, the administration of a lethal dose of Russell's viper or E. carinatus venom to rhesus monkeys resulted in hemorrhages in the kidneys and other organs in all animals, and mild acute tubular necrosis in $20 \%$ of animals, within $24 \mathrm{hrs}$ of envenomation. After a sub-lethal venom dose, however, more than $50 \%$ of animals developed acute tubular necrosis, and fibrin thrombi were demonstrable in $50-75 \%$ of glomeruli. ${ }^{6}$

To obtain further information about direct toxicity of Russell's viper venom (RVV) in renal tissue, Willinger et al studied the combined functional and morphologic changes in isolated perfused rat kidney, complemented by studies in renal epithelial and mesangial cell cultures. RVV administration induced changes in renal plasma flow, glomerular filtration rate; filtration fraction and tubular reabsorption of sodium were reduced, and fractional excretion of sodium and water showed an increase. Both oliguria and a subsequent polyuric phase could be demonstrated. ${ }^{7}$

On morphological analysis, the most prominent structural lesions were observed in the renal cortex. Extensive damage and loss of glomerular epithelial cells and endothelium was detected with only the basement membrane remaining. Ballooning and even rupture of glomerular capillaries could be seen. ${ }^{8}$

Another prominent feature of RVV action is on renal cortex and other renal zones, concerned vessels with muscular walls (arteries, veins, arterioles, venules). The venom led to complete lysis of vascular smooth muscle cells leaving behind only the basement membrane. Varying degrees of epithelial injury occurred in all tubular segments. In cell culture studies, RVV induced a complete disintegration of confluent mesangial cell layers at lower concentration. In epithelial cell cultures however, only extremely high doses of RVV led to microscopically discernible damage. ${ }^{8}$

\section{Objective}

To analyze various factors influencing the outcome in patients of snakebite with acute kidney injury.

\section{Materials and Methods}

The present prospective study was conducted by the Department of Emergency Medicine at M S Rammaih Medical College, Bengaluru, India from August 2017 to September 2018.

A total of 100 study subjects who met the inclusion criteria were included in the study.

\section{Inclusion Criteria}

Patients with snakebite, developing Acute Kidney Injury as defined in the following table: ${ }^{9}$

\begin{tabular}{|c|c|c|}
\hline \multicolumn{2}{|c|}{ Proposed Classification of Acute Kidney Injury - Modified Rifle Criteria } \\
\hline Stage & Serum Creatinine Clearance & Urine Output Criteria \\
\hline 1 (Risk) & Increase of $\geq 0.3 \mathrm{mg} / \mathrm{dL}$ or $1.5-2$ fold increase of the baseline & $<0.5 \mathrm{ml} / \mathrm{Kg} / \mathrm{h}>6 \mathrm{hr}$ \\
\hline 2 (Injury) & Increase to $2-3$ fold of the baseline & $<0.5 \mathrm{ml} / \mathrm{Kg} / \mathrm{h} \mathrm{for}>12 \mathrm{hr}$ \\
\hline 3 (Failure) & $\begin{array}{c}\text { Increase to }>3 \text { fold or serum creatinine } \geq 4 \mathrm{mg} / \mathrm{dL} \text { with an } \\
\text { acute rise of atleast } 0.5 \mathrm{mg} / \mathrm{dL} .\end{array}$ & $\begin{array}{c}0.3 \mathrm{ml} / \mathrm{kg} / \mathrm{hr} \text { for } 24 \mathrm{hr} \text { or anuria for } \\
12 \mathrm{hr} .\end{array}$ \\
\hline
\end{tabular}




\section{Exclusion Criteria}

The patients who were known hypertensive and/or diabetic on treatment, chronic history of NSAID intake, patients with past history of renal disease and previous diagnosed chronic kidney disease or contracted kidney on abdominal ultrasound were excluded from the study.

A thorough physical examination was done to look for local and systemic features of envenomation. Site of snakebite was examined for presence of fang marks, cellulitis, bleeding from site of bite, local necrosis, blistering, gangrene, regional lymph node enlargement, and evidence for compartment syndrome. All vital signs were looked for. features of bleeding manifestations: gum bleeding, epistaxis, ecchymosis and features of neuroparalysis and uremic symptoms were looked for in all the subjects who were included in the study.

\section{Investigations}

All the subjects who were selected for the purpose of the study underwent detailed laboratory investigation including complete blood count along with bleeding and clotting time. Urine sample was examined for the presence of albumin, sugar, and RBC deposits. Blood urea and serum creatinine were estimated to know about the renal function. Electrocardiogram and USG abdomen were done. CT Brain was done when required based on the requirements.

All the tests were done at the time of the admission, and further tests were done as per clinical requirement.

Patients underwent physical examination daily. Pulse rate, Blood pressure, Urine output, Respiratory rate and features of envenomation were monitored daily. Blood specimen was taken every day till discharge or death to measure sodium, potassium, urea, creatinine, bleeding time, clotting time, platelets and for patients undergoing dialysis, pre-dialysis and post-dialysis Urea and Creatinine was measured for each cycle.

Outcome of the patients was evaluated observing the condition of the patient at the time of discharge or death in the hospital.

Statistical analysis was carried out with the help of SPSS (version 20) for Windows package (SPSS Science, Chicago, IL, USA). The description of the data was done in the form of mean +/- SD for quantitative data while in the form of $\%$ proportion for qualitative (categorical) data. $P$-values of $<0.05$ was considered significant. Chi square test (or Fisher's exact test in case of small frequencies in cell) was used to examine the associations between qualitative/ quantitative variables.

\section{Result}

A total of 100 study subjects were evaluated and data were analysed for outcome: Survival or death. Out of the 100 patients in this study, 62 patients survived and 38 patients died. Mortality rate was found to be around $38 \%$.

In our study of 100 patients, age of the patient ranges from 12-65 yrs as mentioned in Table 1 . In the study, nearly $54 \%$ of participants were male and $46 \%$ female.

Table I.Demographic Profile of the Study Subjects

\begin{tabular}{|c|c|c|c|}
\hline & & Survived & Died \\
\hline \multirow{4}{*}{$\begin{array}{c}\text { Age } \\
\text { Group }\end{array}$} & $<20$ years & 14 & 2 \\
\cline { 2 - 4 } & $20-40$ years & 32 & 10 \\
\cline { 2 - 4 } & $41-60$ years & 9 & 21 \\
\cline { 2 - 4 } & $>60$ years & 7 & 5 \\
\hline \multirow{2}{*}{ Gender } & Male & 34 & 20 \\
\cline { 2 - 4 } & Female & 28 & 18 \\
\hline
\end{tabular}

Species of snake was identified as viper in 60 patients (44 patients with Russell Viper bite and 16 patients with saw scaled Viper bite) and in case of remaining 40 patients, species could not be identified.

Table 2.Distribution of Study Subjects Based on the Species of Snakebite

\begin{tabular}{|c|c|}
\hline Species of Snake & Number (\%) \\
\hline Russell viper & $44(44 \%)$ \\
\hline Saw scaled viper & $16(16 \%)$ \\
\hline Unidentified & $40(40 \%)$ \\
\hline
\end{tabular}

Table 3.Clinical Manifestations of the Study Subjects

\begin{tabular}{|c|c|c|c|c|}
\hline & & $\begin{array}{c}\text { Survived } \\
\mathbf{( N = 6 2 )}\end{array}$ & $\begin{array}{c}\text { Died } \\
\mathbf{( N = 3 8 )}\end{array}$ & \\
\hline Cellulitis & Present & $\begin{array}{c}60 \\
(96.7 \%)\end{array}$ & $\begin{array}{c}38 \\
(100 \%)\end{array}$ & 0.524 \\
\hline $\begin{array}{c}\text { Bleeding } \\
\text { manifestation }\end{array}$ & Present & $4(6.4 \%)$ & $\begin{array}{c}14 \\
(36.8 \%)\end{array}$ & 0.0004 \\
\hline Hypotension & $\begin{array}{c}\text { Hypot- } \\
\text { ension }\end{array}$ & $\begin{array}{c}16 \\
(25.8 \%)\end{array}$ & $\begin{array}{c}30 \\
(78.9 \%)\end{array}$ & 0.0001 \\
\hline $\begin{array}{c}\text { Bite to ASV } \\
\text { Time (Early) }\end{array}$ & $\begin{array}{c}<6 \\
\text { hours }\end{array}$ & $\begin{array}{c}54 \\
(81.1 \%)\end{array}$ & $\begin{array}{c}10 \\
(26.4 \%)\end{array}$ & 0.0001 \\
\hline
\end{tabular}

In our study of 100 patients of snakebite with acute kidney injury, 18 patients had bleeding manifestations (haematuria, gum bleeding, hematemesis), out of which 14 died. By using chi square test, $p$ value of 0.0004 was obtained which shows that there was a statistically significant relationship between the patients developing bleeding manifestations and mortality. Using chi square test, $p$ value of 0.524 was obtained for cellulitis which showed that there was no statistically significant association between patients having Cellulitis with mortality. 
Out of 46 patients who presented with hypotension (systolic $<90 \mathrm{mmHg}$ ), 16 survived and remaining 30 died. By using chi square test, $p$ value of $<0.0001$ (very significant) was obtained. This showed that there was a strong statistically significant association between hypotension and mortality.

Out of total of 64 patients who received ASV early (bite to ASV time <6hrs), 54 (84.3\%) patients survived and 10 patients died. Among those who died 28 (73.6\%) of them had got anti-snake venom after 6 hours of snakebite and $10(26.4 \%)$ patients received within 6 hours of snakebite. The association between time of ASV administration and survival was found to be statistically significant.

Out of the 100 patients, 60 patients required dialysis and remaining 40 patients were treated conservatively. Peritoneal dialysis alone was done in 34 patients and both peritoneal and hemodialysis was done in 26 patients. Out of 60 patients who required dialysis (PD/HD), 46 (76.6\%) patients survived and 14 patients died. Out of 38 patients who died, 8 had evidence of cortical necrosis and all the 38 subjects had bilateral congested kidneys, on autopsy.

\section{Discussion}

100 patients with history of snakebite and presence of acute kidney injury were analysed in the present study. The distribution of age and gender in the present study was found to be comparable to the study findings of Suchitra et al. (58\% men and 52\% were between $31-50$ years $)^{10}$ and Ganesh et al., ${ }^{11}$ (Mean Age was 39.1 years and $56.7 \%$ were males) study.

In our study, the most common species causing acute kidney injury was Viper. The above inference is similar to the findings of studies done by Athappan et al. ${ }^{11}$ (95\%), Suchitra et al. ${ }^{10}(84 \%)$, Ali et al. $(76 \%)^{12}$ and Chen et al. ${ }^{13}$

In our study, the mortality rate was $38 \%$. This is one inference in our study which does not fall in line with the results of other studies where it was $22.5 \%$ in Athappan $\mathrm{G}$ et al., ${ }^{11} 25 \%$ in Ali et al. ${ }^{13}$ and 28.65 in Chugh et al. ${ }^{14}$ Increased mortality rate in our study was not a direct mortality, other factors like the distance from the site of bite to the hospital, the delay in transportation, and approaches of the local traditional healers, and even unavailability of anti-snake venom in smaller hospital resulted in delayed arrival of the patient to the centre and hence the delayed administration of anti-snake venom.

In our study, all patients except two developed cellulites. This study showed that cellulitis does not correlate with mortality which is similar to the study findings of Athappam et al. ${ }^{11}$ (survived $99.9 \%$ and died $97.2 \%$ ).

The association of Bleeding manifestation and hypotension with the mortality in the present study was found to be statistically significant which was similar and comparable to the study findings of Suchitra et al. ${ }^{10}$ and Ali et al. ${ }^{12}$

In our study, 64 patients received ASV within 6 hours of snakebite. This study showed that late therapy with ASV, i.e., after 6 hours of bite was strongly associated with mortality. This finding was found to be comparable with the findings of Looareesuwan et al., ${ }^{15} \mathrm{Jin}$-Bor Chen et al., ${ }^{13}$ and Al Homrany et al. ${ }^{16}$

The findings of cortical necrosis in the kidney autopsy was found to be similar to the study findings of Chung et al. ${ }^{14}$ Another study done by Chugh et al. ${ }^{17}$ also found that ten cases had bilateral renal cortical necrosis out of 45 cases with snakebite and renal failure.

\section{Conclusion}

In the present study, viper bite accounted for definite acute kidney injury. Major risk factors linked with adverse outcome in snakebite-related acute kidney injury were hypotension, bleeding manifestations, and delayed specific therapy with ASV. Age, gender, and presence of cellulitis did not influence the mortality in patients with acute kidney injury. Early therapy with Anti-snake venom was associated with better outcome in terms of mortality. All patients with acute kidney injury showed autopsy findings of renal involvement.

\section{Conflict of Interest: None}

\section{References}

1. Bawaskar HS, Bawaskar PH. Profile of Snake envenoming in Western Maharashtra, India. Trans Roy Soc Trop Med Hyg. 2002;96:79-84. [PubMed] [Google Scholar]

2. White J. Bites and Stings from venomous animals; a global overview. Ther Drug Monit. 2000;22:65-8. [Google Scholar]

3. Ratcliffe PJ, Pukrittayakamee S, Ledingham JG, Warrell DA. Direct nephrotoxicity of Russell's viper venom demonstrated in the isolated perfused rat kidney. Am J Trop Med Hyg .1989;40:312-9. [Google Scholar]

4. Bawaskar HS. Snake venoms and antivenom; critical supply issues. J Assoc Phy India .2004; 52; 14-8. [Google Scholar]

5. Aung W, Kyaw KP, Hla B, Aye SS, Naing SP, Kyaw A, Swe TN. Renal involvement in Russel's viper bite patients without disseminated intravascular coagulation. Trans $R$ Soc Trop Med Hyg. 1998; 92:322-4. [PubMed] [Google Scholar]

6. Jeyarajah R. Russell's viper bite in Sri Lanka. A study of 22 cases. Am J Trop Med Hyg. 1984;33:506-10. [PubMed] [Google Scholar]

7. Willinger CC, Thamaree S, Schramek H, Gstraunthaler G, Pfaller W. In vitro nephrotoxicity of Russell's viper venom. Kidney Int. 1995;47:518-28. [PubMed] [Google Scholar]

8. Vyacheslav Y. Melnikov, Bruce A. Molitoris. 
Improvements in the Diagnosis of Acute Kidney Injury. Saudi J Kid Dis Transp. 2008; 19(4): 537-544. [Google Scholar]

9. Seedat YK, Reddy J, Edington DA. Acute renal failure due to proliferative nephritis from snakebite poisoning. Nephron. 1974;13:455-63. [Google Scholar]

10. Suchithra N, Pappachan JM, Sujathan P. Snakebite Envenoming in Kerala, South India: Clinical profile and factors involved in adverse outcomes. EMJ. 2008; 25: 200-204. [PubMed] [Google Scholar]

11. Athappan G, Balaji MV, Navaneethan U. Acute Renal Failure in Snake Envenomation: A large Prospective Study. Saudi J Kidney Dis Transpl. 2008;19(3):404-410. [PubMed] [Google Scholar]

12. Ali G, Kak M, Kumar M, Bali SK, Tak SI, Hassan G, Wadhwa MB. Acute Renal Failure following Echis Carinatus envenomation. Indian J Nephrol .2004; 14: 177-181. [Google Scholar]

13. Chen JB, Leung J, Hsu KT. Acute Renal Failure after Snakebite: A Report of Four Cases. Chin Med J (Taipei).1997;59:65-9. [Google Scholar]

14. Chugh KS, Aikat BK, Sharma BK, Dash SC, Mathew MT, Das KC. Acute Renal Failure Following Snakebite. Am J Trop Med Hyg.1975;24(4):692-697. [PubMed] [Google Scholar]

15. Looareesuwan S, Viravan C, Warrell DA. Factors contributing to fatal snakebite in the rural tropics: analysis of 46 cases in Thailand. Trans-R-Soc-Trop-MedHyg. .1988; 82(6): 930-4. [PubMed] [Google Scholar]

16. Al-Homrany MA. Acute Renal Failure due to Snakebite: Clinical aspects. Saudi J Kidney Dis Transplant. 1999;9(4):285-9. [Google Scholar]

17. Chugh KS, Pal Y, Chakravarty RN, Datta BN, Mehta R, Sakhuja V, Mandal AK, Sommers SC. Acute renal failure following poisonous snakebite. Am J Kidney Dis. 1984 Jul;4(1):30-8. [PubMed] [Google Scholar] 